\title{
Beyond Telomerase: Telomere Instability as a Novel Target for Cancer Therapy
}

Maria Fadri-Moskwik, Qing Zhou and Weihang Chai*

Section of Medical Sciences and School of Molecular Biosciences, Washington State University, USA

\begin{abstract}
Telomeres are areas of heterochromatin composed of TTAGGG repeats located at the ends of linear chromosomes. They play a critical role in keeping genome stable and preventing premature aging diseases and the development of cancer. Characterizing mechanisms of telomere maintenance and understanding how their deregulation contributes to human diseases are therefore important for developing novel therapies. A key mechanism driving telomere maintenance and replicative immortality in cancer cells is telomere elongation by telomerase, and many emerging potential telomere-based therapies have focused on targeting telomerase components. By contrast, recent studies on telomere maintenance mechanism suggest that disrupting telomere stability by interfering with alternative mechanisms of telomere synthesis or protection may also yield new strategies for the treatment of cancer. This review will focus on emerging regulators of telomere synthesis or maintenance, such as G4 telomeric DNA, the CST complex, the t-loop, and shelterins, and discuss their potential as targets for anti-cancer chemotherapeutic intervention in the future.
\end{abstract}

\section{Telomeres are Important for Genomic Stability and Prevention of Human Diseases}

In humans, telomeres are areas of heterochromatin composed of TTAGGG repeats located at the ends of linear chromosomes. Components of telomeres are TTAGGG repeats [1], nucleosomes [2], t-loop [3], and telomere binding proteins [4]. Telomeres have three functions: first, telomeres protect the ends of chromosomes and facilitate their replication by telomerase; second, telomeres prevent recognition of chromosome ends as breaks and suppress DNA damage response (DDR) [5,6]; and last, recent work suggests that telomeres are emerging as potential sensors of genotoxic stress [7]. Deregulation of telomere maintenance, or telomere instability, is directly associated with many diseases such as cancer [8], dyskeratosis congenita $[9,10]$, idiopathic pulmonary fibrosis [11,12], Coats Plus disease [13], aplastic anemia [14], as well as bone marrow failure [15] and premature aging syndromes [16]. On a molecular level, telomere instability can lead to genomic instability and is associated with genomic defects such as telomere shortening, telomere fusions, and chromosomal rearrangements $[17,18]$. Therefore, it is important to understand the mechanisms of telomere maintenance and how telomere instability, which contributes to human diseases and genomic instability, may arise.

Telomere instability can arise from several mechanisms (Figure 1A). First, telomeres gradually shorten with each cell division as a part of normal cellular aging process due to the end-replication problem and telomere end resection [19]. When telomeres become critically short, short telomeres are sensed as damaged DNA, inducing cell cycle arrest that leads to senescence in normal somatic cells. If the $\mathrm{p} 53$ or $\mathrm{Rb}$ checkpoint pathway is deficient, cells continue to divide and the short unstable telomeres induce chromosome end-to-end fusions, leading to genome instability that drives oncogenesis. On the other hand, after a cell becomes a cancer cell, it needs a mechanism to maintain/ restore telomere length in order to be immortal. To do so, cancer cells either express telomerase [20] or initiate a recombination-dependent alternative-lengthening-of-telomeres (ALT) pathway [21].

Pathological telomere shortening can arise due to problems with telomere synthesis such as defects in telomere replication, extension of G-strand by telomerase, and/or C-strand fill-in by DNA polymerase (Pol) [22-25]. In addition to telomere shortening, telomere instability can also occur when inappropriate secondary structures of telomere DNA, such as G-quadruplexes, form. Formation of these structures can interfere with telomere DNA synthesis by stalling replication forks at the telomeric region $[26,27]$, leading to telomere fragility and possibly rapid loss of telomeres or elevated recombination [28-33].

In addition to telomere shortening, telomere instability can also result from telomere deprotection induced by deficiency in telomere binding proteins due to loss of DDR suppression and increased genomic rearrangements [34-36] (Figure 1B). For example, deletion of the shelterin TRF1 in mice activated DDR and increased sistertelomere fusions, chromosome end-to-end fusions, and telomere fragility [18]. Furthermore, telomere-induced chromosomal instability associated with TRF1 deletion contributed to early developing of skin tumorigenesis in a p53-/- background [18]. In addition, deletion of another shelterin, Potla, in mouse cells resulted in aberrant homologous recombination at telomeres and increased various cytogenetic abnormalities such as q-q arm chromosomal fusions without telomeric signals at fusion sites, isochromatid ring chromosomes completely devoid of telomeres, isochromatid ring chromosome without telomeres at sites of fusion, chromosomal fragment without telomeres, telomere fragments containing leading and lagging telomeric DNA, lagging telomeric fragments, and isochromatid breaks [36]. Importantly, the genomic instability resulting from Pot1a deletion was associated with increased tumorigenicity as Pot1a-/- MEF's exhibited increased foci formation and skin tumor formation in a p53-/- background [36]. Furthermore, because DNA damage at telomeres is less likely to be

${ }^{*}$ Corresponding author: Dr. Weihang Chai, Section of Medical Sciences and School of Molecular Biosciences, Washington State University, Spokane, PO Box 1495, WA 99210, USA, Tel: (509)-358-7575; Fax: (509)-358-7627; E mail: wchai@wsu.edu

Received October 31, 2013; Accepted December 05, 2013; Published December 09, 2013

Citation: Fadri-Moskwik M, Zhou Q, Chai W (2013) Beyond Telomerase: Telomere Instability as a Novel Target for Cancer Therapy. J Mol Genet Med 7: 91 doi: 10.4172/1747-0862.1000091

Copyright: () 2013 Fadri-Moskwik M, et al. This is an open-access article distributed under the terms of the Creative Commons Attribution License, which permits unrestricted use, distribution, and reproduction in any medium, provided the original author and source are credited 


\section{A)}
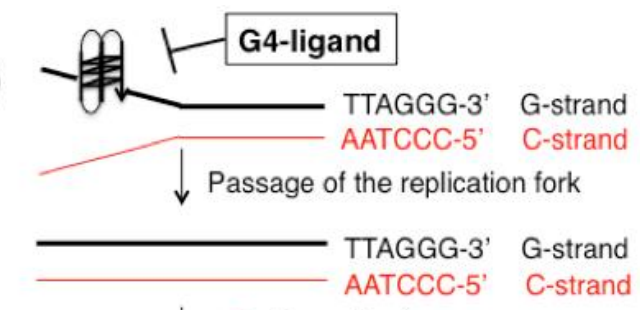

Resection by

Nucleases

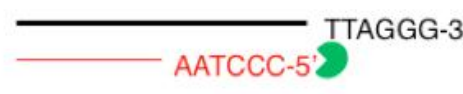

G4-ligand

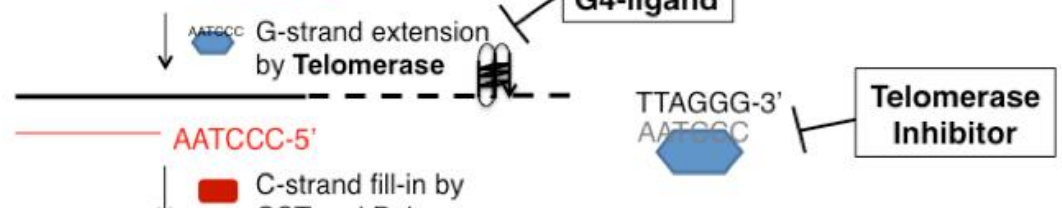

CST and Pol- $\alpha$

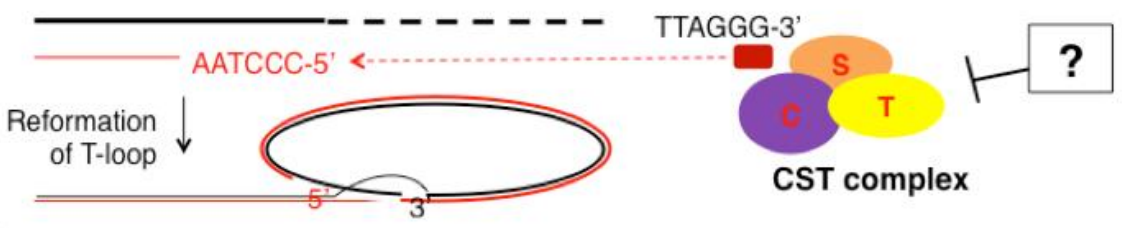

B)

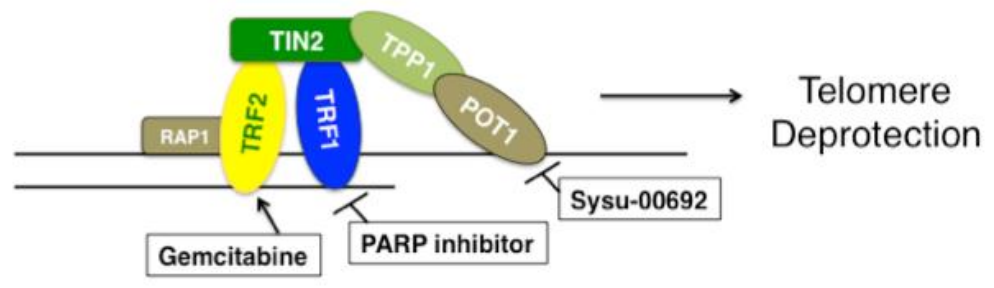

\section{C)}

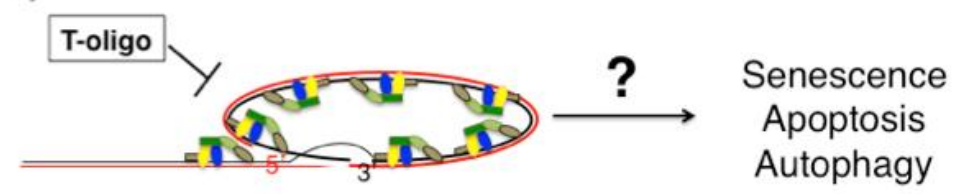

Figure 1: Mechanisms of Telomere Instability (A) Molecular targets that directly affect telomere integrity. G4-ligands can bind to telomere DNA and induce formation of or stabilize the G-quadruplex structure, which can block telomere DNA synthesis as well as inhibit telomerase extension of telomeres. Telomerase inhibitors that target either the hTR or hTERT subunit directly inhibit telomere extension, therefore disrupting telomere maintenance. The CST complex regulates C-strand synthesis, defect in which may de-regulate telomerase activity or induce rapid telomere loss when telomerase is inhibited. (B) Shelterins protect telomere ends, and drugs that target shelterins may disrupt telomere protection. (C) T-oligos can induce senescence, apoptosis, and autophagy in vitro through a to-be-defined mechanism.

repaired [37], accumulation of telomere damage can be a source of genomic instability in cells.

\section{Molecular Therapies to Directly Regulate Telomere Integrity}

Because telomere stability contributes to replication immortality in cancer cells, targeting telomere stability by interfering with telomere synthesis or protection may yield new strategies for the treatment of cancer. Molecular targets that play a direct role in maintaining telomere integrity are telomere DNA, telomere synthesis, and telomere protection (Table 1).

\section{Telomere DNA Targets}

G-quadruplex: Human telomere DNA is composed of a long DNA strand of guanine-rich tandem-repeat sequences (G-strand), and a shorter, complementary cytosine-rich strand (C-strand). Numerous proteins bind to telomere DNA and protect telomeres by preventing aberrant activation of DNA damage signaling at telomeres. However, certain small molecules can compete with these proteins for binding to telomere DNA and/or induce G-strand formation of the G-quadruplex (G4) secondary structure via Hoogsteen hydrogen bonding [38]. These small molecules, or G4 ligands, can disrupt telomere synthesis and maintenance by interfering with telomere elongation by telomerase [39] 


\begin{tabular}{|c|c|c|c|c|}
\hline Target & Mechanism & Compound & Clinical Trial & Reference \\
\hline \multirow[t]{3}{*}{ Telomere DNA } & \multirow{3}{*}{$\begin{array}{l}\text { inducing the formation of or } \\
\text { stabilizing G- quadruplex }\end{array}$} & BRACO-19 & No & 43 (review) \\
\hline & & RHPS4 & No & 43 (review) \\
\hline & & Quarfloxin & Yes & 44 \\
\hline \multirow[t]{3}{*}{ Telomerase } & hTR & Imetelstat & Yes & $50,66-69$ \\
\hline & \multirow[t]{2}{*}{ Inhibiting hTERT } & $\mathrm{AZT}$ & approved for HIV & 52,53 \\
\hline & & BIBR1532 & No & $54-58$ \\
\hline CST complex & Ctc1, Stn1, Ten1 & N/A & N/A & N/A \\
\hline \multirow{2}{*}{ Shelterins } & \multirow{2}{*}{$\begin{array}{l}\text { blocking Pot1 binding to telo- } \\
\text { meres stabilizing TRF2 }\end{array}$} & SYSU-00692 & No & 68 \\
\hline & & Gemcitabine & $\begin{array}{l}\text { approved for pancreatic cancer, breast can- } \\
\text { cer, ovarian cancer, and lung cancer }\end{array}$ & 69,70 \\
\hline T-loop & destabilizing t-loop structure & t-oligos & No & $73-83$ \\
\hline Post- translational Modifications & TRF1-PARsylation & PARP inhibitor & Yes & 88 \\
\hline
\end{tabular}

Table 1: Telomere integrity.

or by exposing telomere ends and activating DNA damage response. G4 ligands have shown promising anti-cancer activity in vitro and in vivo, leading to a search for small molecules that can selectively interact with and stabilize G-quadruplexes (for reviews, see [40,41]). Although several classes of G4 stabilizing molecules have been described [42], two severe limitations thus far with these compounds are lack of potency and relatively poor selectivity for binding to G-quadruplex versus duplex DNA [42]. Two newly described quadruplex-binding acridine ligands, BRACO-19 and RHPS4, however, can induce rapid replicative senescence in cancer cells and activate the same DNA damage response that follows DNA double-strand breaks [43]. One G4 stabilizing molecule, quarfloxin, was tested in phase II clinical trials for the treatment of neuroendocrine/carcinoid tumors, however, its mechanism of action seemed dependent, not on telomere instability, but on inhibition of G-quadruplexes involved in Pol I-dependent transcription [44].

\section{Telomere synthesis targets}

Telomerase: Telomerase, a ribonucleoprotein DNA polymerase that synthesizes telomeres de novo, is over expressed in the majority of cancer cells [45]. Telomerase is composed of two core components: the reverse transcriptase hTERT and its associated template RNA, hTR. Currently, several classes of compounds that target either hTR or hTERT are being tested for their ability to inhibit telomerase and limit tumor growth. First, the most attractive emerging candidate to inhibit hTR, a N3'-P5' thio-phosphoramidate named GRN163 or Imetelstat, competes with telomeric primer binding by hybridizing to hTR and inhibiting telomerase activity [46-49]. In vitro characterization of Imetelstat showed that it inhibits telomerase, induces telomere shortening, senescence, or apoptosis [50], and can reduce tumor growth in a DU145 mouse xenograft model of prostate cancer [50]. Excitingly, results from clinical trials show evidence for the potential utility of Imetelstat for treating hematological cancers and, possibly, a subset of patients whose solid lung tumors had short telomeres [51]. By contrast, other inhibitors target hTERT. A thymidine analogue, 3'-Azido-2',3'dideoxythymidine (AZT) was found in $\mathrm{CHO}$ cells to incorporate preferentially at telomeres, and its incorporation can be telomerasemediated [52]. Although the precise mechanism of action of AZT on telomerase remains elusive [52], it is interesting to note that treatment with AZT could produce effective inhibition of telomerase activity in varied cell lines as well as progressive telomere shortening and cytotoxic effects, although such effects are cell line dependent [53]. By contrast, another small molecule, BIBR1532, is a non-nucleosidic compound that directly binds and effectively inhibits hTERT by interfering with its enzymatic processivity [54], thus inducing telomere shortening and senescence in human cancer cells in vitro [55]. Compared to untreated controls, treatment with BIBR1532 of late-passage, telomere shortened, HT1080-derived xenografts in mice reduced initial tumor growth and decreased the incidence of tumors larger than $1000 \mathrm{~mm} 3$ [56]. The most recent work on BIBR1532 suggest that BIBR1532 may be particularly promising when given in combination with traditional chemotherapeutic agents [57,58].

CST complex: Composed of three proteins, Ctc1, Stn1, and Ten1, the human and mammalian CST complex binds to telomeres and is involved in telomere synthesis. In budding yeast, CST (Cdc13/Stn1/ Ten1) acts as a telomere-capping complex that protects telomeres [5961] and regulates telomere extension by telomerase [62]. Although in mammals, CST is not needed for telomere capping, the key function of mammalian CST is facilitating replication of telomere DNA, mediating C-strand fill-in $[23,30,63,64]$, and inhibiting excessive telomerase extension of G-strand [65]. Interestingly, mammalian CST is also important for protecting the stability of non-telomeric DNA $[23,30,63]$. Such protection may be due to the role of CST in genomic DNA replication re-start after hydroxyurea (HU) induced fork stalling [63]. Although there are not any current cancer therapies that specifically target CST, the recent elucidation of a high-resolution structure of human Stn1-Ten1 complex may provide enough data for scientists to begin rational drug design of CST-targeting agents [66]

\section{Telomere protection targets}

Shelterin proteins protect the ends of telomeres from genomic rearrangements: Another strategy to target telomere stability is to enhance or reactivate growth suppressive responses induced by telomere defects. Composed of the six proteins, TRF1, TRF2, TIN2, RAP1, POT1, and TPP1, the shelterin complex binds to telomeres, and protects telomeres by repressing DNA damage response at telomeres and preventing chromosome fusions $[5,6,67]$. Loss of shelterins derepresses DDR and allows non-homologous end joining (NHEJ) of chromosome ends, resulting in chromosome end-to-end fusions and genomic instability $[17,18,35,36]$.

Targeting shelterin proteins as an approach of cancer therapies has emerged recently. For example, one shelterin Pot 1 is targeted by a berberine derivative, Sysu-00692, which binds to Pot 1 and interferes with the interaction between Pot1 and telomere DNA as observed by chromatin immunoprecipitation (ChIP) in vitro [68]. This compound also slightly inhibits telomerase in A549 cells and decreases cell proliferation in HL60 and A549 cancer cells [68].

Recent study indicates that another shelterin, TRF2, may be a potential target of cancer therapy. The potent anti-tumor drug gemcitabine is a nucleoside analogue that is currently approved for 
use against ovarian, breast, NSCLC, and pancreatic cancers. Although gemcitabine acts by incorporating into DNA in place of cytosine and inhibiting DNA replication, this drug can also induce XPF-dependent telomere loss by stabilizing TRF2 [69]. Interestingly, recent work shows that metronomic treatment with this drug has anti-angiogenic effects in a pancreatic cancer model [70]. However, caution is needed when applying drugs targeting shelterin components in anti-cancer therapy, because the shelterin proteins are essential for maintaining telomere stability in normal cells as well.

\section{T-loops may repress telomere-dysfunction induced foci (TIF) formation at telomere ends}

The duplex lariat structure of the t-loop forms when the single strand 3' G-overhang invades double-stranded telomeric repeats by base pairing with the C-strand and displacing the G-strand [4]. TRF2 has been shown in vitro to be sufficient for the formation of t-loop [3,71]. Recently, a three-state model of telomere protection was proposed [67]. Although hypothetical, according to this model, formation of the t-loop conceals linear chromosome ends into the telomeric repeats, thereby protecting chromosome ends from being recognized as damaged DNA. By contrast, loss of the t-loop would result in linearization of chromosome ends, activation of ATM and p53, and the formation of foci of aggregated DNA damage proteins. These foci, known as telomere-dysfunction induced foci or TIF, contain DNA repair factors such as 53BP1, - H2AX, Rad17, ATM, and the Mre11/ Rad50/Nbs1 complex [72]. Thus, loss of the t-loop would result in linearization of chromosome ends, initiating DNA damage signaling and growth suppressive responses such as cell cycle arrest, senescence, or apoptosis in the absence of gross chromosomal rearrangements.

In support of this model, it has been shown that T-oligos, or oligonucleotides with homology to the G-rich strand of the t-loop, can induce senescence in human fibroblasts in a p53 and Rb dependent manner, consistent with telomere loop disruption [73]. Furthermore, treatment with T-oligos can induce apoptosis, senescence, or autophagy in a variety of cancer cell lines [74-79]. T-oligos can also inhibit angiogenesis in melanoma SCID xenografts [80]. Also, pre-treatment of cancer cells with T-oligos can confer radiosensitivity upon mammary carcinoma cells and in in vivo mouse mammary tumor models [81]. Importantly, the helicase WRN seems to play a role in T-oligo induced DNA damage response, as T-oligo treated fibroblasts deficient of WRN have reduced phosphorylation of $\mathrm{p} 53$ and H2AX [82]. Finally, the most recent work shows that inhibition of tankyrase can block DNA damage induction by T-oligos, suggesting that recruitment of shelterins away from telomeres by T-oligos may be needed for T-oligo induced DNA damage in MU, PM-WK, and MM-MC melanoma cells [83]. Although further work is needed to understand the mechanism of t-loops in telomere protection in vivo, these data suggest that T-oligos may induce growth suppression and DNA damage response by allowing an intermediate state of telomere deprotection.

\section{Molecular Therapies to Regulate Cell Fate in Response to Telomere Instability}

\section{Telomere-binding proteins as information node between} telomeres and cell fate decisions

At the interface of cell signaling and telomere regulation, telomerebinding proteins may integrate cell biological inputs to regulate telomere synthesis and protection, functioning as the "information node". As outlined in an excellent recent review [84], telomere binding proteins are subject to post-translational modification (PTM) by kinases, sumoylases, acetylases, and ubiquitin ligases. Phosphorylation, sumoylation, acetylation, or ubiquitination can dynamically regulate telomere-binding protein function or activity in response to cellular stimuli. Thus, characterization of the PTM's that regulate telomere binding protein function or activity may allow scientists to change the information at the telomere-cell node to alter cell fate.

Currently, a few PTM's and their enzymes are known to regulate telomere function. First, shelterin components TRF1 and TRF2 are known to be phosphorylated, sumoylated, ubiquitinated, poly(ADPribosyl)ated (PARsylated), and methylated by a variety of enzymes $[84,85]$. These PTM's of TRF1 and TRF2 regulate many aspects of TRF1 and TRF2 function at telomeres including telomeric DNA binding, TRF1 or TRF2 stability, protein-protein interactions, and priming of TRF1 for subsequent PTM's. Importantly, tankyrase, the poly(ADP-ribose) polymerase (PARP) that catalyzes TRF1 PARsylation and releases TRF1 from telomeres [86], is an emerging target for cancer therapy [87], and PARP inhibitors are in clinical trials for the treatment of cancer [88]. Excitingly, recent work also have shown that acetylation of TRF2 by p300 regulates TRF2 stability and telomere binding, and that overexpression of an acetyl-defective TRF2 mutant induces altered telomeres, telomeric DNA damage response, and senescence [89]. Another shelterin protein, TPP1, was recently shown to be phosphorylated by Cdk1, and this phosphorylation event appears to regulate telomerase recruitment to telomeres [90]. Because pharmacological inhibitors of many enzymes that catalyze PTM's are commercially available, increased knowledge of the PTM's that regulate telomere synthesis and protection may allow scientists to alter the telomere status and replicative immortality of cancer cells by inhibiting the enzymes that catalyze the PTM's of telomere binding proteins.

\section{Outlook and Conclusions}

\section{Telomeres as sensors of genotoxic stress}

As telomere based therapies move from bench to bedside, understanding the targets and the mechanisms by which new therapies act will be important to optimizing their clinical use. Also, as the mechanisms that maintain telomere integrity are elucidated, learning how cells respond and adapt to changes in telomere status will yield a broader perspective on the role of telomeres in replicating cells. For example, it was recently shown that DNA damage at telomeric DNA is irreparable and causes persistent activation of DNA damage response [37]. Furthermore, in ageing and stress-induced senescence, telomeres can be preferred targets of DNA damage response [91]. Finally, work from the Karlseder lab recently showed that telomere deprotection was functionally distinct from genomic DNA damage response [92]. Together, these results suggest that, in contrast to genomic DNA, telomeres may function as specialized sensors of cellular [67] or genotoxic stress [7] that can induce the senescence or inhibit cell proliferation [7].

\section{Chemotherapy: beyond telomerase inhibition}

A key mechanism driving replicative immortality in cancer cells is telomere elongation by telomerase [8], thus many current potential telomere based therapies have focused on targeting active components of telomerase. As knowledge of the regulation of telomere maintenance increases, however, other molecular targets that regulate telomere synthesis or cellular response to telomere status have emerged as potential regulators of replicative immortality in cancer cells. Importantly, these emerging regulators of telomere maintenance, G4 
telomeric DNA, the CST complex, the t-loop, or shelterins, may be potential targets for chemotherapeutic agents for cancer in the future.

\section{References}

1. Moyzis RK, Buckingham JM, Cram LS, Dani M, Deaven LL, et al. (1988) A highly conserved repetitive DNA sequence, (TTAGGG)n, present at the telomeres of human chromosomes. Proc Natl Acad Sci USA 85: 6622-6626.

2. Lejnine S, Makarov VL, Langmore JP (1995) Conserved nucleoprotein structure at the ends of vertebrate and invertebrate chromosomes. Proc Natl Acad Sci U S A 92: 2393-2397.

3. Griffith JD, Comeau L, Rosenfield S, Stansel RM, Bianchi A, et al. (1999) Mammalian telomeres end in a large duplex loop. Cell 97: 503-514.

4. De Lange $T$ (2005) Shelterin: the protein complex that shapes and safeguards human telomeres. Genes Dev 19: 2100-2110.

5. Denchi EL (2009) Give me a break: how telomeres suppress the DNA damage response. DNA Repair (Amst) 8: 1118-1126.

6. Karlseder J, Broccoli D, Dai Y, Hardy S, De Lange T (1999) p53- and ATMdependent apoptosis induced by telomeres lacking TRF2. Science 283 $1321-1325$

7. Van Tuyn J, Adams PD. (2012) Signalling the end of the line. Nat. Cell Biol. 14: 339-341.

8. Hanahan D, Weinberg RA (2011) Hallmarks of cancer: the next generation Cell 144: 646-674

9. Nelson ND, Bertuch AA (2011) Dyskeratosis congenita as a disorder of telomere maintenance. Mutat. Res. 730: 43-51.

10. Keller RB, Gagne KE, Usmani GN, Asdourian GK, Williams DA et al. (2012) CTC1 Mutations in a patient with dyskeratosis congenita. Pediatr Blood Cance 59: $311-314$

11. Armanios MY, Chen JJ, Cogan JD, Alder JK, Ingersoll RG, et al. (2007) Telomerase mutations in families with idiopathic pulmonary fibrosis. $\mathrm{N}$ Engl $\mathrm{J}$ Med 356: 1317-1326

12. Tsakiri KD, Cronkhite JT, Kuan PJ, Xing C, Raghu G, et al. (2007) Adult-onse pulmonary fibrosis caused by mutations in telomerase. Proc Natl Acad Sci U S A 104: 7552-7557.

13. Anderson BH, Kasher PR, Mayer J, Szynkiewicz M, Jenkinson EM et al. (2012) Mutations in CTC1, encoding conserved telomere maintenance component 1 cause Coats plus. Nat Genet 44: 338-342.

14. Vulliamy T, Marrone A, Dokal I, Mason PJ (2002) Association between aplastic anaemia and mutations in telomerase RNA. Lancet 359: 2168-2170.

15. Walne AJ, Bhagat T, Kirwan M, Gitiaux C, Desguerre I, et al. (2013) Mutations in the telomere capping complex in bone marrow failure and related syndromes. Haematologica 98: 334-338.

16. Sahin E, DePinho RA. (2012) Axis of ageing: telomeres, p53 and mitochondria Nat. Rev. Mol. Cell Biol. 13: 397-404.

17. Rai R, Zheng H, He H, Luo Y, Multani A, et al. (2010) The function of classical and alternative non-homologous end-joining pathways in the fusion of dysfunctional telomeres. EMBO J 29: 2598-2610.

18. Martínez P, Thanasoula M, Munoz P, Liao C, Tejera A, et al. (2009) Increased telomere fragility and fusions resulting from TRF1 deficiency lead to degenerative pathologies and increased cancer in mice. Genes Dev 23: 2060-2075.

19. Allsopp RC, Chang E, Kashefi-Aazam M, Rogaev El, Piatyszek MA, et al. (1995) Telomere shortening is associated with cell division in vitro and in vivo. Exp Cell Res 220: 194-200.

20. Morin GB (1989) The human telomere terminal transferase enzyme is a ribonucleoprotein that synthesizes TTAGGG repeats. Cell 59: 521-529.

21. Bryan TM, Englezou A, Gupta J, Bacchetti S, Reddel RR. (1995) Telomere elongation in immortal human cells without detectable telomerase activity. EMBO J 14: 4240-428

22. Zhao Y, Sfeir AJ, Zou Y, Buseman CM, Chow TT, et al. (2009) Telomere extension occurs at most chromosome ends and is uncoupled from fill-in in human cancer cells. Cell 138: 463-475.

23. Huang C, Dai X, ChaiW. (2012) Human Stn1 protects telomere integrity by promoting efficient lagging-strand synthesis at telomeres and mediating C-strand fill-in. Cell Res. 22: 1681-1695

24. Dai X, Huang C, Bhursari A, Sampathi S Schubert K et al. (2010) Molecular steps of G-overhang generation at human telomeres and its function in chromosome end protection. Eur Mol Biol Organ J 29: 2788-2801.

25. Chow TT, Zhao Y, Mak SS, Shay JW, Wright WE. (2012) Early and late steps in telomere overhang processing in normal human cells: the position of the final RNA primer drives telomere shortening. Genes Dev 26: 1167-1178.

26. Chen Y, Qu K, Zhao C, Wu L, Ren J, et al. (2012) Insights into the biomedical effects of carboxylated single-wall carbon nanotubes on telomerase and telomeres. Nat Commun 3: 1074

27. Wang Q, Liu JQ, Chen Z, Zheng KW, Chen CY, et al. (2011) G-quadruplex formation at the 3' end of telomere DNA inhibits its extension by telomerase, polymerase and unwinding by helicase. Nucleic Acids Res 86: 1-12.

28. Lin W, Sampathi S, Dai H, Liu C, Zhou M, et al. (2013) Mammalian DNA2 helicase/nuclease cleaves G-quadruplex DNA and is required for telomere integrity. EMBO J 32: 1425-1439.

29. Gu P, Chang S (2013) Functional characterization of human CTC1 mutation reveals novel mechanisms responsible for the pathogenesis of the telomere disease Coats plus. Aging Cell 12: 1100-1109.

30. Gu P, Min JN, Wang Y, Huang C, Peng T, et al. (2012) CTC1 deletion results in defective telomere replication, leading to catastrophic telomere loss and stem cell exhaustion. EMBO J 31: 2309-2321.

31. Sfeir A, Kosiyatrakul ST, Hockemeyer D, MacRae SL, Karlseder J, et al. (2009) Mammalian telomeres resemble fragile sites and require TRF1 for efficient replication. Cell 138: 90-103.

32. Uringa EJ, Lisaingo K, Pickett HA, Brind'Amour J, Rohde JH, et al. (2012) RTEL1 contributes to DNA replication and repair and telomere maintenance. Mol. Biol. Cell 23: 2782-2792.

33. Vannier JB, Pavicic-Kaltenbrunner V, Petalcorin MIR, Ding $\mathrm{H}$, Boulton SJ. (2012) RTEL1 dismantles T loops and counteracts telomeric G4-DNA to maintain telomere integrity. Cell 149: 795-806.

34. Okamoto K, Bartocci C, Ouzounov I, Diedrich JK, Yates JR $3^{\text {rd }}$, et al. (2013) A two-step mechanism for TRF2-mediated chromosome-end protection. Nature 494: 502-505.

35. Denchi EL, de Lange T. (2007) Protection of telomeres through independent control of ATM and ATR by TRF2 and POT1. Nature 448: 1068-71.

36. Wu L, Multani AS, He H, Cosme-Blanco W, Deng Y, et al. (2006) Pot1 deficiency initiates DNA damage checkpoint activation and aberrant homologous recombination at telomeres. Cell 126: 49-62.

37. Fumagalli M, Rossiello F, Clerici M, Barozzi S, Cittaro D, et al. (2012) Telomeric DNA damage is irreparable and causes persistent DNA-damage-response activation. Nat. Cell Biol 14: 355-365.

38. Biffi G, Tannahill, D, McCafferty J, Balasubramanian S. (2013) Quantitative visualization of DNA G-quadruplex structures in human cells. Nat. Chem 5 182-186.

39. Zahler AM, Williamson JR, Cech TR, Prescott DM. (1991) Inhibition of telomerase by G-quartet DNA structures. Nature 350: 718-720.

40. Mergny JL, Hélène C (1998) G-quadruplex DNA: a target for drug design. Nat Med 4: 1366-1367.

41. Kerwin SM (2000) G-Quadruplex DNA as a target for drug design. Curr. Pharm. Des. 6: $441-478$.

42. Gowan SM, Harrison JR, Patterson L, Valenti M, Read MA et al. (2002) A G-Quadruplex-Interactive Potent Small-Molecule Inhibitor of Telomerase Exhibiting in vitro and in vivo Antitumor Activity. Mol Pharmacol 61: 1154-1162.

43. Artese A, Costa G, Ortuso F, Parrotta L, Alcaro S. (2013) Identification of New Natural DNA G-Quadruplex Binders Selected by a Structure-Based Virtual Screening Approach. Molecules 18: 12051-12070.

44. Balasubramanian S, Hurley LH, Neidle S. (2011) Targeting G-quadruplexes in gene promoters: a novel anticancer strategy? Nat. Rev. Drug Discov. 10 261-275.

45. Ouellette MM, Wright WE, Shay JW. (2011) Targeting telomerase-expressing cancer cells. J. Cell. Mol. Med. 15: 1433-1442. 
46. Goldblatt EM, Gentry ER, Fox MJ, Gryaznov SM, Shen C, et al. (2009) The telomerase template antagonist GRN163L alters MDA-MB-231 breast cance cell morphology, inhibits growth, and augments the effects of paclitaxel. Mol. Cancer Ther. 8: 2027-2035.

47. Gryaznov SM, Jackson S, Dikmen G, Harley C, Herbert BS, et al. (2007) Oligonucleotide conjugate GRN163L targeting human telomerase as potential anticancer and antimetastatic agent. Nucleosides. Nucleotides Nucleic Acids 26: 1577-1579.

48. Herbert BS, Gellert GC, Hochreiter A, Pongracz K, Wright WE, et al. (2005) Lipid modification of GRN163, an N3'-->P5' thio-phosphoramidate oligonucleotide, enhances the potency of telomerase inhibition. Oncogene 24: 5262-5268.

49. Hochreiter AE, Xiao H, Goldblatt EM, Gryaznov SM, Miller KD, et al. (2006) Telomerase template antagonist GRN163L disrupts telomere maintenance, tumor growth, and metastasis of breast cancer. Clin. Cancer Res. 12: 3184-3192.

50. Asai A, Oshima Y, Yamamoto Y, Uochi TA, Kusaka H, et al. (2003) A nove telomerase template antagonist (GRN163) as a potential anticancer agent. Cancer Res 63: 3931-3939.

51. Williams SC (2013) No end in sight for telomerase-targeted cancer drugs. Nat Med 19: 6

52. Gomez DE, Armando RG, Alonso DF (2012) AZT as a telomerase inhibitor Front. Oncol 2: 113.

53. Murakami J, Nagai N, Shigemasa K, Ohama K. (1999) Inhibition of Telomerase Activity and Cell Proliferation by a Reverse Transcriptase Inhibitor in Gynaecological Cancer Cell Lines. Eur J Cancer 35: 8-15.

54. Pascolo E, Wenz C, Lingner J, Hauel N, Priepke H, et al. (2002) Mechanism of human telomerase inhibition by BIBR1532, a synthetic, non-nucleosidic drug candidate. J Biol Chem 277: 15566-72.

55. Satyanarayana A, Manns MP, Rudolph KL. (2004) Telomeres, telomerase and cancer: an endless search to target the ends. Cell Cycle 3: 1138-1150.

56. Damm K, Hemmann U, Garin-Chesa P, Hauel N, Kauffmann I, et al. (2001) A highly selective telomerase inhibitor limiting human cancer cell proliferation. EMBO J 20:6958-6968.

57. Bashash D, Ghaffari SH, Zaker F, Kazerani M, Hezave K, et al. (2013) BIBR 1532 increases arsenic trioxide-mediated apoptosis in acute promyelocytic leukemia cells: therapeutic potential for APL. Anticancer. Agents Med Chem 13: $1115-1125$.

58. Meng E, Taylor B, Ray A, Shevde LA, Rocconi RP. (2012) Targeted inhibition of telomerase activity combined with chemotherapy demonstrates synergy in eliminating ovarian cancer spheroid-forming cells. Gynecol Oncol 124: 598-605.

59. Grandin N, Reed SI, Charbonneau M. (1997) Stn1, a new Saccharomyces cerevisiae protein, is implicated in telomere size regulation in association with Cdc13. Genes Dev 11: 512-527.

60. Grandin N, Damon C, Charbonneau M. (2001) Cdc13 prevents telomere uncapping and Rad50-dependent homologous recombination. EMBO J. 20: 6127-6139.

61. Pennock E, Buckley K, Lundblad V. (2001) Cdc13 delivers separate complexes to the telomere for end protection and replication. Cell 104: 387-96.

62. Puglisi A, Bianchi A, Lemmens L, Damay P, Shore D. (2008) Distinct roles for yeast Stn1 in telomere capping and telomerase inhibition. EMBO J 27: 2328-2339.

63. Stewart JA, Wang F, Chaiken MF, Kasbek C, Chastain PD 2nd, et al. (2012) Human CST promotes telomere duplex replication and general replication restart after fork stalling. EMBO J 31: 3537-49.

64. Wang F, Stewart JA, Kasbek C, Zhao Y, Wright WE, et al. (2012) Human CST has independent functions during telomere duplex replication and $\mathrm{C}$-strand fillin. Cell Rep. 2: 1096-1103.

65. Chen LY, Redon S, Lingner J. (2012) The human CST complex is a terminator of telomerase activity. Nature 488: 540-544.

66. Bryan C, Rice C, Harkisheimer M, Schultz DC, Skordalakes E. (2013) Structure of the human telomeric Stn1-Ten1 capping complex. PLoS One 8: e66756.

67. Cesare AJ, Karlseder J. (2012) A three-state model of telomere control over human proliferative boundaries. Curr. Opin. Cell Biol 24: 731-738.

68. Xiao N, Chen S, Ma Y, Qiu, J, Tan JH, et al. (2012) Interaction of Berberine derivative with protein POT1 affect telomere function in cancer cells. Biochem. Biophys Res Commun 419: 567-572.

69. Su CH, Chu WC, Lan KH, Li CP, Chao Y, et al. (2012) Gemcitabine causes telomere attrition by stabilizing TRF2. Eur J Cancer 48: 3465-3474.

70. Laquente B, Lacasa C, Ginesta MM, Casanovas O, Figueras A, et al. (2008) Antiangiogenic effect of gemcitabine following metronomic administration in a pancreas cancer model. Mol. Cancer Ther. 7: 638-647.

71. Stansel RM, de Lange T, Griffith JD. (2001) T-loop assembly in vitro involves binding of TRF2 near the 3' telomeric overhang. EMBO J 20: 5532-5540.

72. Takai H, Smogorzewska A, de Lange T. (2003) DNA damage foci at dysfunctional telomeres. Curr Biol 13: 1549-1556.

73. Li GZ, Eller MS, Hanna K, Gilchrest BA. (2004) Signaling pathway requirements for induction of senescence by telomere homolog oligonucleotides. Exp Cell Res 301: $189-200$

74. Puri N, Eller MS, Byers HR, Dykstra S, Kubera J, et al. (2004) Telomere-based DNA damage responses: a new approach to melanoma. FASEB J 18: 1373-81.

75. Yaar M, Eller MS, Panova I, Kubera J, Wee LH, et al. (2007) Telomeric DNA induces apoptosis and senescence of human breast carcinoma cells. Breast Cancer Res 9: R13.

76. Aoki H, Iwado E, Eller MS, Kondo Y, Fujiwara K, et al. (2007) Telomere 3 overhang-specific DNA oligonucleotides induce autophagy in malignant glioma cells. FASEB J. 21: 2918-2930.

77. Gnanasekar M, Thirugnanam S, Zheng G, Chen A, Ramaswamy K. (2009) T-oligo induces apoptosis in advanced prostate cancer cells. Oligonucleotides 19: $287-292$.

78. Longe HO, Romesser PB, Rankin AM, Faller DV, Eller MS, et al. (2009) Telomere homolog oligonucleotides induce apoptosis in malignant but not in normal lymphoid cells: mechanism and therapeutic potential. Int J Cancer 124 473-482.

79. Sarkar S, Faller DV. (2011) T-oligos inhibit growth and induce apoptosis in human ovarian cancer cells. Oligonucleotides 21: 47-53.

80. Coleman C, Levine D, Kishore R, Qin G, Thorne T, et al. (2010) Inhibition of melanoma angiogenesis by telomere homolog oligonucleotides. J Oncol. 2010, 928628

81. Weng D, Cunin MC, Song B, Price BD, Eller MS, et al. (2010) Radiosensitization of mammary carcinoma cells by telomere homolog oligonucleotide pretreatment. Breast Cancer Res. 12, R71.

82. Eller MS, Liao X, Liu S, Hanna K, Backvall H, et al. (2006) A role for WRN in telomere-based DNA damage responses. Proc Natl Acad Sci U SA 103 15073-1508.

83. Pitman RT, Wojdyla L, Puri N (2013) Mechanism of DNA damage responses induced by exposure to an oligonucleotide homologous to the telomere overhang in melanoma. Oncotarget 4: 761-771.

84. Peuscher MH, Jacobs JJ (2012) Posttranslational control of telomere maintenance and the telomere damage response. Cell Cycle 11: 1524-1534.

85. Walker JR, Zhu XD (2012) Post-translational modifications of TRF1 and TRF2 and their roles in telomere maintenance. Mech Ageing Dev 133: 421-34.

86. Chang W, Dynek JN, Smith S (2003) TRF1 is degraded by ubiquitin-mediated proteolysis after release from telomeres. Genes Dev. 17: 1328-1333.

87. Lehtiö L, Chi NW, Krauss S (2013) Tankyrases as drug targets. FEBS J 280: 3576-93.

88. Fong PC, Boss DS, Yap TA, Tutt A, Wu P, et al. (2009) Inhibition of poly(ADPribose) polymerase in tumors from BRCA mutation carriers. N Engl J Med 361 123-134.

89. Her YR, Chung IK (2013) p300-mediated acetylation of TRF2 is required for maintaining functional telomeres. Nucleic Acids Res 41: 2267-2283.

90. Zhang Y, Chen LY, Han X, Xie W, Kim H, et al. (2013) Phosphorylation of TPP1 regulates cell cycle-dependent telomerase recruitment. Proc. Natl. Acad. Sci. U.S. A. $110: 5457-5462$

91. Hewitt G, Jurk D, Marques FD, Correia-Melo C, Hardy T, et al. (2012) Telomeres are favoured targets of a persistent DNA damage response in ageing and stress-induced senescence. Nat. Commun. 3: 708 .

92. Cesare AJ, Hayashi MT, Crabbe L, Karlseder J (2013) The telomere deprotection response is functionally distinct from the genomic DNA damage response. Mol Cell 51: 141-155. 